\title{
Production and Characterisation of Microfine Sized Palm Oil Fuel Ash (POFA) Originated from Bau, Lundu Palm Oil Mill
}

\author{
R. Ahmadi ${ }^{1}$, , M.S.Saiful ${ }^{1}$, D.F Zawawi ${ }^{1}$, S.Z.A. Rahman ${ }^{1}$, I. Ismail ${ }^{1}$, A.B. Mannan ${ }^{1}$ and A.S.Z. Abidin ${ }^{2}$ \\ ${ }^{1}$ Department of Civil Engineering, University Malaysia Sarawak, 94300 Samarahan, Sarawak, Malaysia \\ ${ }^{2}$ Department of Mechanical and Manufacturing Engineering, University Malaysia Sarawak, 94300 Samarahan, Sarawak, Malaysia
}

\begin{abstract}
This paper investigates an effective and economical way for laboratory scale production of micro fine sized palm oil fuel ash (POFA) using an electric powder grinder. The raw POFA obtained from the palm oil mill is initially grinded by using Los Angeles abrasion machine, and then sieved using $150 \mu \mathrm{m}$ sieve before it is burned in a furnace at $500^{\circ} \mathrm{C}$. The burned POFA is then grinded using electric powder grinder to obtain the targeted micro fine sized. The physical, morphological and chemical properties of the micro fine sized POFA produced are analysed in the form of cement paste using Particle Size Analyzer (PSA), nitrogen sorption by using BET method, Fourier Transform Infrared Spectroscopy (FT-IR) and Scanning Electron Microscopy (SEM) with Energy Dispersive Spectroscopy (EDS). The results show that $96 \%$ micro fine sized POFA is produced when using the optimum grinding process. The microstructural analyses of cement paste with $20 \%$ micro fine sized POFA replacement give the optimum results that contribute to higher compressive strength. The overall results of this research show that the optimum grinding process by using electric powder grinder is relevant and can be used as pioneering work in the concrete production industry.
\end{abstract}

\section{Introduction}

In countries like Malaysia, Thailand and Indonesia, palm oil is one of the main agroindustries which produces a large amount of waste in the form of kernel shell, empty fruit bunches and fibers [2]. These by-products are used as fuel to heat up boiler for generation of electricity in the palm oil mill. As the second largest palm oil producer in the world, Malaysia has generated million tonnes of palm oil wastes each year $[1,3,12]$. The extracted product from the boiling process is known as palm oil fuel ash (POFA) which comprises a large amount of silica, thus, possesses pozzolanic properties suitable as cement replacement material.

Previous studies have showed that POFA can be used as a partial cement replacement material to produce high strength concrete with higher impermeability and durability [8]. The inclusion of up to $40 \%$ micro fine POFA tends to increase the workability and viscosity of high strength concrete and could improve the corrosion resistance properties of steel inside concrete $[4,5,6,7,9,13,14]$. Furthermore, utilization of POFA as partial cement replacement materials contributes to the development of concrete with resistance to adverse environment condition $[10,11]$.

Until now, the best method of producing finer size of POFA particle size $(1-10 \mu \mathrm{m})$ is still unavailable. Although previous studies are able to produce micro fine sized POFA, the cost of production is still too expensive and the methods used are considered not effective $[3,13]$. Due to the significance contribution of micro fine sized POFA as a new potential cement replacement material, an effective and economical method to produce micro

${ }^{a}$ Corresponding author araudhah@unimas.my 
fine sized POFA is investigated. This research focuses on the simple and optimum grinding process and further investigates the physical and morphological properties of micro fine sized POFA which can affect the strength, workability and hardened concrete properties.

\section{Materials and experimental procedures}

\subsection{Materials}

The cement used in this experiment is Ordinary Portland Cement Type 1 whereas the Palm oil fuel ash (POFA) is obtained from Bau, Lundu Palm Oil Mill, Sarawak, Malaysia. The POFA is subjected to the $1^{\text {st }}$ stage of grinding by using Los Angeles abrasion machine and sieved through $150 \mu \mathrm{m}$ sieve to remove coarser particles. Next, POFA is burned at $500^{\circ} \mathrm{C}$ for 1 hour in a furnace to remove excessive unburned carbon. Then, it is subjected to $2^{\text {nd }}$ stage of grinding by using electric powder grinder with 25000rpm to obtain micro fine sized which is ranging from 1-10 $\mu \mathrm{m}$.

\subsection{Experimental procedures}

In order to determine the effectiveness of electric powder grinder, 2 samples were used which are; Sample A, $500 \mathrm{~g}$ of burned POFA and Sample B, $1000 \mathrm{~g}$ of burned POFA. All cement paste specimens were prepared with water to cement ratio of 0.35 . One control sample and four samples were casted by replacing the cement with $10 \%, 20 \%, 30 \%$ and $40 \%$ of micro fine POFA (sample A). The test specimens were cured in water for 28 days.

The Particle Size Analyzer (PSA) was used to determine the physical size of burned POFA after $2^{\text {nd }}$ stage of grinding. The morphology of cement paste was investigated by using Scanning Electron Microscopy (SEM) with Energy Dispersive Spectroscopy (EDS). Fourier Transforms Infrared Spectroscopy (FT-IR) analysis is carried out to identify the pozzolanic characteristic in terms of hydration and identification of the composite group. Nitrogen sorption by using BET method is conducted to obtain the precise specific area of cement paste powder. Ordinary Portland Cement (OPC) and fly ash (FA) are also used as control samples.

\section{Results and discussions}

\subsection{Particle Size Analysis (PSA)}

\subsubsection{Sample A}

In this process, $500 \mathrm{~g}$ of burned POFA is grinded for 10 cycles which takes a duration of 30 minutes in total. After the $10^{\text {th }}$ cycles of grinding are completed, the final amount of POFA collected is $490 \mathrm{~g}$. Therefore, $10 \mathrm{~g}$ POFA loss is equivalent to $2 \%$ of the total amount of sample used. Micro fine particles of POFA is seen to slightly escaped from the tighten lid of the grinder during the grinding and while opening the lid after the grinding process.

\subsubsection{Sample B}

In this process, $1000 \mathrm{~g}$ of burned POFA is used and grinded for 15 cycles which takes a duration of 45 minutes in total. After the $15^{\text {th }}$ cycles of grinding are completed, the final amount of POFA collected is $960 \mathrm{~g}$. Therefore, $40 \mathrm{~g}$ POFA loss is equivalent to $4 \%$ of the total amount of sample used. The particle losses is also due to the same reason as in sample A. The $\mathrm{d}_{50}(\mu \mathrm{m})$ particle sizes of OPC and FA, $18.29 \mu \mathrm{m}$ and $8.64 \mu \mathrm{m}$ respectively are also determined to compare the different sizes of POFA, OPC and FA. Table 1.1 shows the particle sizes result for every cycle while, Figure 1.1 shows the Particle size $d_{50}(\mu \mathrm{m})$ versus amount of cycles. 


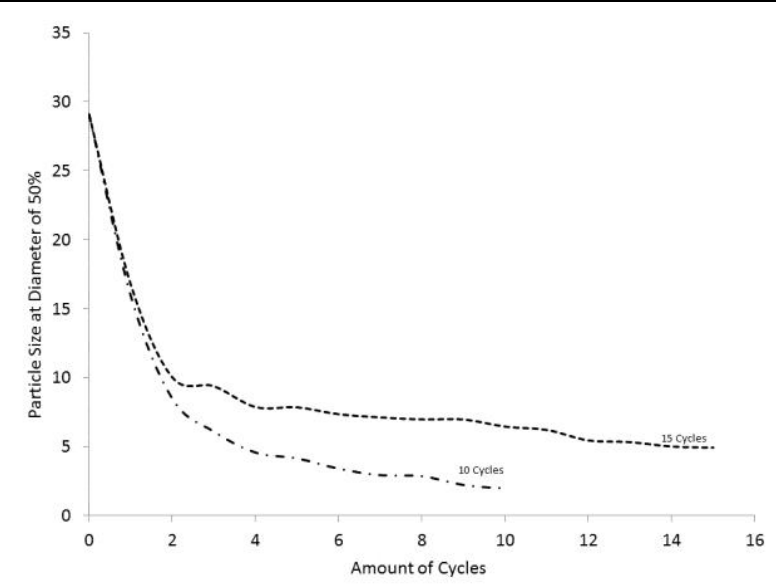

Figure 1.1: Particles Size at Diameter 50\% vs Amount of cycles

Table 1.1 Particles Size Result for Samples A \& B

\begin{tabular}{|c|c|c|c|c|c|c|}
\hline Samples & \multicolumn{3}{|c|}{$\mathrm{A}$} & \multicolumn{3}{|c|}{ B } \\
\hline Cycles & $\begin{array}{c}\text { Particle } \\
\text { Size } \\
\mathrm{d}_{50} \\
(\mu \mathrm{m})\end{array}$ & $\begin{array}{c}\text { Mean } \\
\text { Diameter } \\
(\mu \mathrm{m})\end{array}$ & $\begin{array}{l}\text { Specific } \\
\text { surface } \\
\left(\mathrm{m}^{2} / \mathrm{g}\right)\end{array}$ & $\begin{array}{c}\text { Particle } \\
\text { Size } \\
\mathrm{d}_{50} \\
(\mu \mathrm{m})\end{array}$ & $\begin{array}{c}\text { Mean } \\
\text { Diameter } \\
(\mu \mathrm{m})\end{array}$ & $\begin{array}{l}\text { Specific } \\
\text { surface } \\
\left(\mathrm{m}^{2} / \mathrm{g}\right)\end{array}$ \\
\hline 0 & 29.09 & 34.51 & 1.117 & 29.09 & 34.51 & 1.117 \\
\hline 1 & 15.97 & 21.38 & 2.296 & 16.78 & 19.67 & 1.555 \\
\hline 2 & 8.49 & 12.10 & 5.782 & 10.04 & 14.24 & 5.058 \\
\hline 3 & 6.10 & 9.07 & 6.415 & 9.39 & 12.30 & 1.705 \\
\hline 4 & 4.58 & 7.04 & 8.627 & 7.88 & 11.59 & 4.766 \\
\hline 5 & 4.16 & 6.27 & 7.135 & 7.86 & 11.72 & 3.736 \\
\hline 6 & 3.41 & 4.35 & 6.071 & 7.36 & 11.47 & 5.093 \\
\hline 7 & 2.94 & 3.70 & 13.288 & 7.13 & 11.03 & 3.125 \\
\hline 8 & 2.87 & 3.15 & 5.798 & 6.98 & 11.74 & 2.775 \\
\hline 9 & 2.67 & 2.90 & 17.893 & 6.98 & 10.14 & 3.927 \\
\hline 10 & 2.23 & 2.41 & 15.871 & 6.46 & 10.77 & 5.286 \\
\hline 11 & & & & 6.22 & 9.37 & 3.700 \\
\hline 12 & & & & 5.46 & 9.32 & 4.138 \\
\hline 13 & & & & 5.34 & 7.95 & 7.834 \\
\hline 14 & & & & 5.02 & 7.52 & 4.530 \\
\hline 15 & & & & 4.94 & 7.38 & 2.583 \\
\hline
\end{tabular}

Micro fine POFA which is ranging from 1-10 $\mu \mathrm{m}$ is obtained in both samples. For both Sample A and Sample B, the optimum cycle of grinding is at $6^{\text {th }}$ and $12^{\text {th }}$ cycles, respectively. This is because the diameter at $10 \%, 50 \%, 90 \%$ and mean diameter is already below $10 \mu \mathrm{m}$. By comparing the POFA diameter at $50 \%$ with OPC and FA, POFA with the highest amount of cycles has the smallest diameter. This factor influenced the surface area of the particle. Smaller particle size contributes to larger surface area and lead to more pore capillaries that can be filled in concrete. Hence, the strength of the hardened concrete will be higher.

\subsection{Fourier Transforms Infrared Spectroscopy (FT-IR)}

Fourier transform infrared spectroscopy (FT-IR) analysis is conducted to identify the pozzolanic characteristics of harden cement paste 
through absorption of infrared spectrum by the formation of main hydration products calcium hydroxide $(\mathrm{CH})$ and calcium silica hydrate (C-S$\mathrm{H})$. A strong band ranging from $965 \mathrm{~cm}^{-1}$ to 975 $\mathrm{cm}^{-1}$ is due to $\mathrm{Si}-\mathrm{O}$ asymmetric stretching vibration of tricalcium silicate, $\mathrm{C}_{3} \mathrm{~S}$ and /or dicalcium silicate, $\mathrm{C}_{2} \mathrm{~S}$ which shows the formation of C-S-H [10]. Figure 1.2 shows the FTIR spectra of cement paste with POFA inclusion at (A) $0 \%$ replacement, (B) $10 \%$ replacement, (C) $20 \%$ replacement, (D) $30 \%$ replacement, (E) $40 \%$ replacement.

A
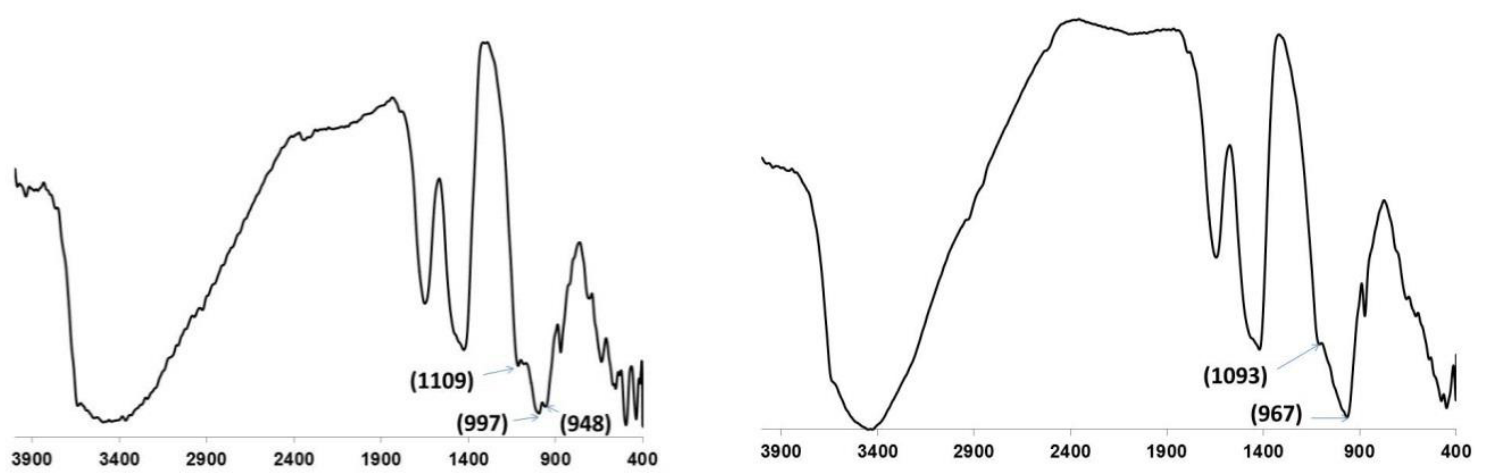

C
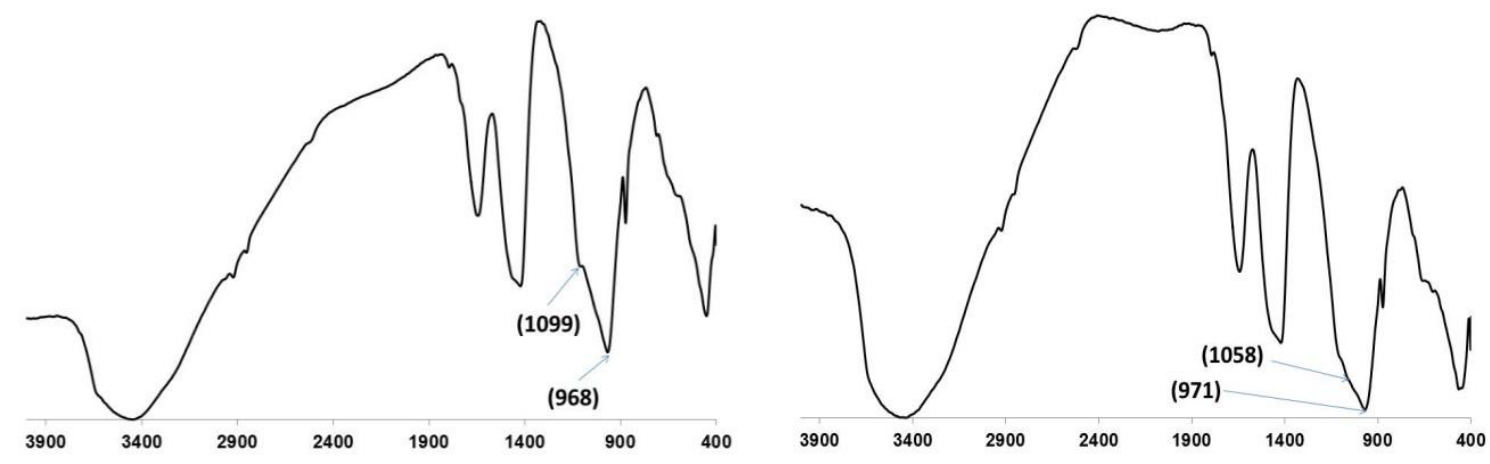

E

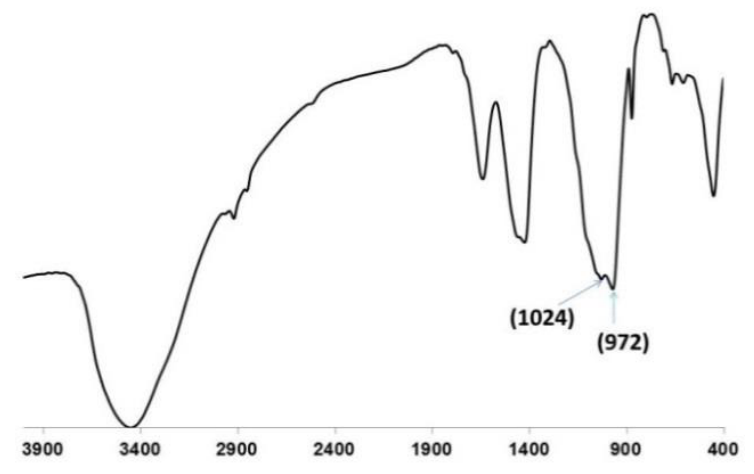

Figure 1.2: FTIR spectra of cement paste with POFA inclusion at (A) $0 \%$ replacement, (B) $10 \%$ replacement, (C) $20 \%$ replacement, (D) $30 \%$ replacement, (E) $40 \%$ replacement.

From Figure 1.2, the strongest absorption band centered at $972 \mathrm{~cm}^{-1}$ to $997 \mathrm{~cm}^{-1}$. Cement paste with $0 \%$ replacement of POFA shows the peak at $948 \mathrm{~cm}^{-1}$ and $997 \mathrm{~cm}^{-1}$ which indicates the paste starts producing the $\mathrm{C}-\mathrm{S}-\mathrm{H}$ gel. As mention earlier the strong band for C-S-H gel is at $965 \mathrm{~cm}^{-1}$ to 975 $\mathrm{cm}^{-1}$. Thus, the spectra show the paste is producing a weak band of C-S-H. Cement paste with $10 \%$ replacement of POFA shows the peak at $967 \mathrm{~cm}^{-1}$ which shows the paste is producing a strong band 
of C-S-H gel. Compare to the $0 \%$ replacement, the peak of $1109 \mathrm{~cm}^{-1}$ decrease to $1093 \mathrm{~cm}^{-1}$. This indicates the extra amount of silica was added from the $10 \%$ of POFA replacement. The similar pattern was observed for $20 \%$ and $30 \%$ replacement. The absorption intensity of the corresponding peak increases with the percentage of replacement indicating the formation of more C$\mathrm{S}-\mathrm{H}$ in the cement paste due to the hydration of $\mathrm{C}_{3} \mathrm{~S}$. Cement paste with $40 \%$ replacement shows a slight increment in peak which is $972 \mathrm{~cm}^{-1}$. This is because of the large amount of POFA powder which takes longer time to contribute in hydration at later stage. Overall, cement paste with $10 \%$, $20 \%$ and $30 \%$ replacement shows the strong band in the formation of the C-S-H gel.
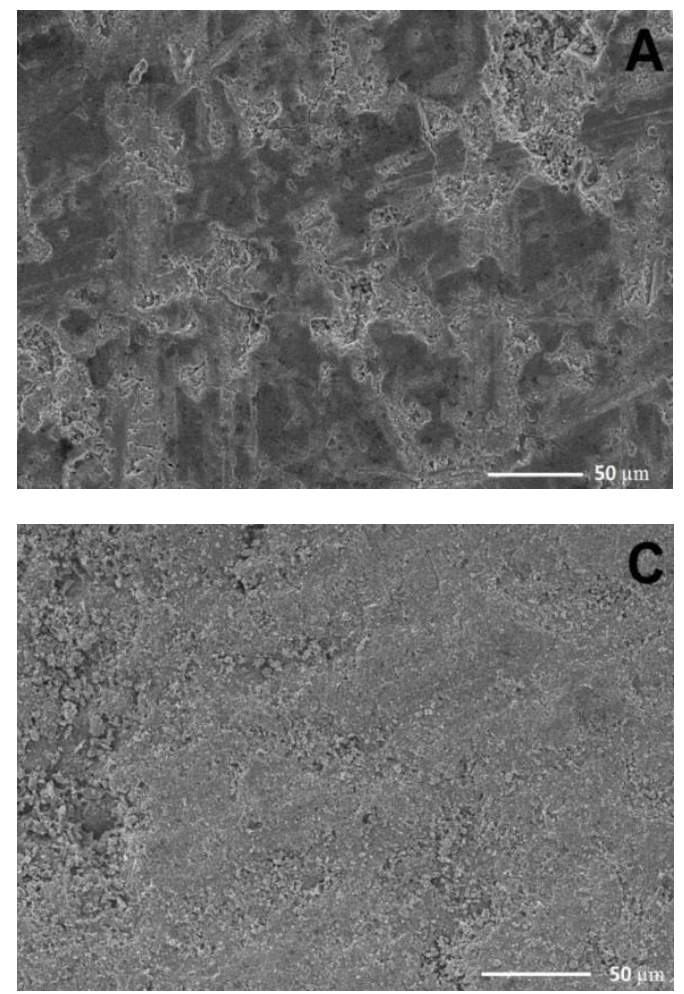

\subsection{Scanning Electron Microscopy (SEM) with Energy Dispersive Spectroscopy (EDS)}

Scanning electron microscopy (SEM) is conducted to obtain the surface morphology of the cement paste while Energy Dispersive Spectroscopy (EDS) is carried out to obtain the chemical composition in the material. Figure 1.3 shows the surface morphology of the cement paste with POFA inclusion at (A) $0 \%$ replacement, (B) $10 \%$ replacement, (C) 20\% replacement, (D) 30\% replacement and (E) 40\% replacement.
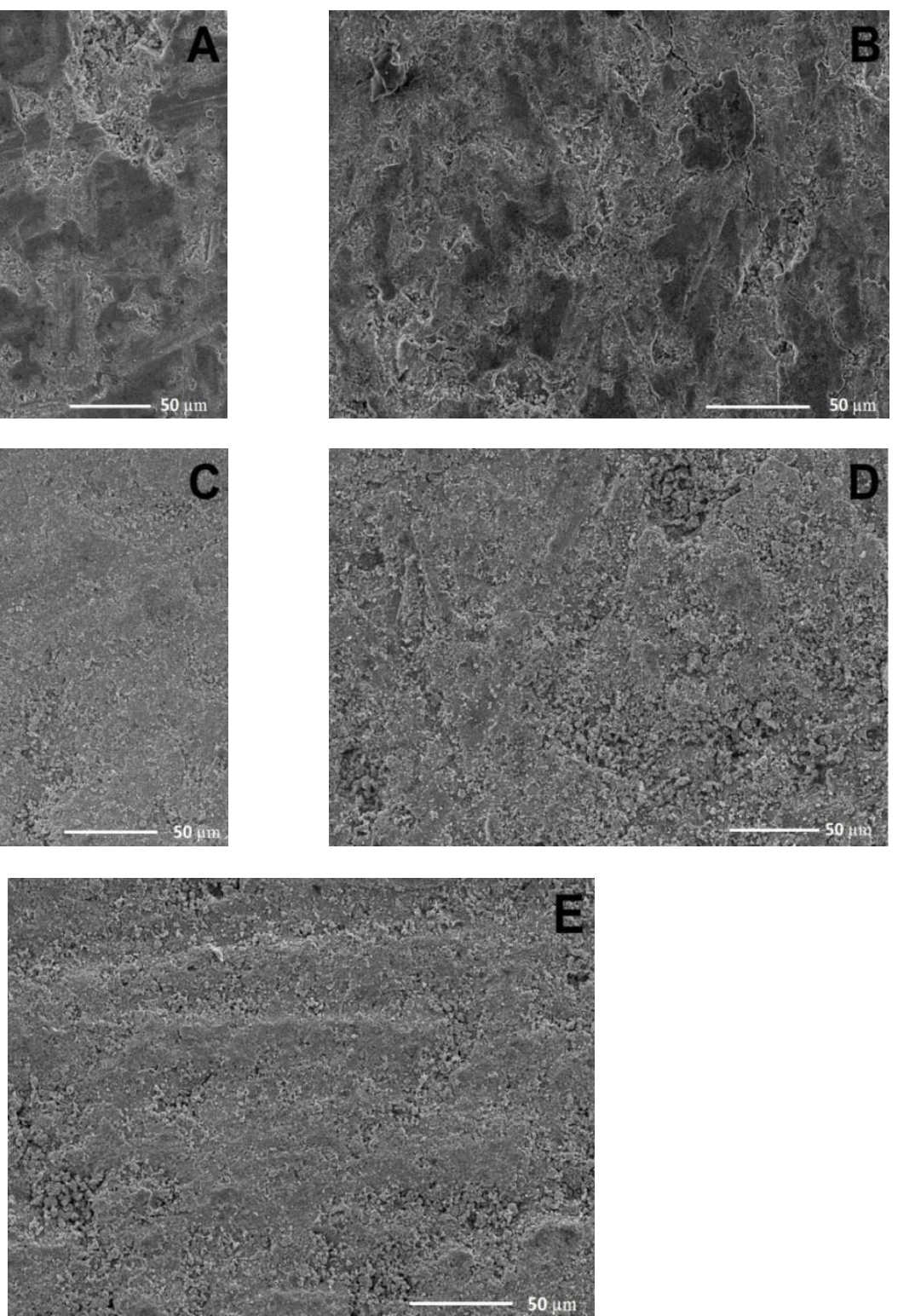

Figure 1.3: Surface morphology of the cement paste at (A) $0 \%$ replacement, (B) $10 \%$ replacement, (C) $20 \%$ replacement, (D) 30\% replacement and (E) $40 \%$ replacement. 
EDS analysis results can be obtained through mapping from the same point used for SEM. Table 1.2 shows the comparison of the $\mathrm{Ca} / \mathrm{Si}$ ratio of cement paste with $0 \%, 10 \%, 20 \%, 30 \%$ and $40 \%$ of POFA replacement.

The results in Table 1.2 show that POFA tend to decrease in $\mathrm{Ca} / \mathrm{Si}$ ratio which indicates pozzolanicity characteristic. The results show that $\mathrm{Ca} / \mathrm{Si}$ ratio is highest in $20 \%$ replacement of POFA, with 4.22 ratios. $\mathrm{Ca} / \mathrm{Si}$ ratio will decrease with the increment of silica present in C-S-H gel [11]. Comparison with compressive strength is also determined. Figure 1.4 shows the compressive strength versus $\mathrm{Ca} / \mathrm{Si}$ ratio for each paste.

Table 1.2: Comparison of $\mathrm{Ca} / \mathrm{Si}$ ratio for each cement paste

\begin{tabular}{|l|l|l|l|}
\hline \multirow{2}{*}{ Sample (28 Days) } & \multicolumn{2}{|l|}{$\begin{array}{l}\text { Element } \\
\text { (atomic \%) }\end{array}$} & \multirow{2}{*}{$\mathrm{Ca} / \mathrm{Si}$} \\
\cline { 2 - 4 } & $\mathrm{Ca}$ & $\mathrm{Si}$ & \\
\hline $0 \%$ & 37.19 & 10.03 & 3.71 \\
\hline $10 \%$ & 36.7 & 11.47 & 3.20 \\
\hline $20 \%$ & $\mathbf{4 4 . 6 7}$ & $\mathbf{1 0 . 5 9}$ & $\mathbf{4 . 2 2}$ \\
\hline $30 \%$ & 35.66 & 12.235 & 2.91 \\
\hline $40 \%$ & 31.6 & 18.613 & 1.70 \\
\hline
\end{tabular}

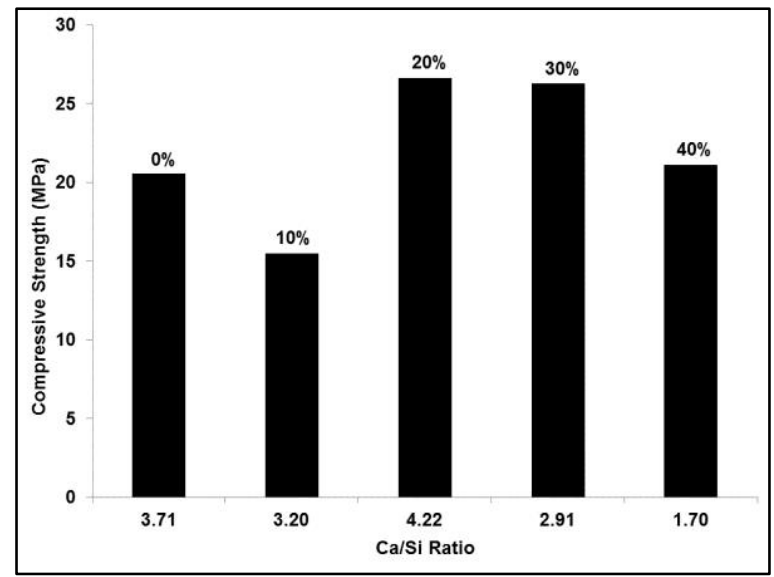

Figure 1.4: Compressive strength vs $\mathrm{Ca} / \mathrm{Si}$ ratio

From Figure 1.4, it is shown that cement paste with $20 \%$ replacement is high in term of compressive strength together with $\mathrm{Ca} / \mathrm{Si}$ ratio. This indicates that there is suitable amount of calcium in cement which contributes to higher initial strengths of concrete. However, as the chemical reactions take place, cracks and shrinkage in concrete might be produced due to the greater heat developed. Therefore, too much Calcium oxide, $\mathrm{CaO}$ is one of the reasons that may lead to failure in concrete. POFA has less calcium content but high in silica. Only with the presence of sufficient calcium and moisture, pozzolanic reaction will takes place resulting in formation of C-S-H gel [6]. This reaction helps to generate secondary C-S-H gel thus producing high strength concrete and makes concrete less destructible compare to OPC concrete. Hence, findings from EDS, supports findings from compressive test and FT-IR analysis.

\subsection{Nitrogen sorption using $\mathrm{BET}_{\mathrm{N} 2}$ analysis}

Nitrogen sorption $\mathrm{BET}_{\mathrm{N} 2}$ is conducted to obtain the precise specific area of cement paste. As shown in Table 1.3, the specific surface areas of POFA paste with inclusion of $10 \%, 20 \%$ and $30 \%$ are higher than $0 \%$ POFA replacement. This is because the micro fine sized POFA is used. Micro fine sized POFA has smaller particle sizes 
compare with OPC which causes it to fill up the capillary pores in cement. Hence, this results in denser internal structure of concrete which could sustain higher capacity load. Since the specific area is greater, the contact surface between pozzolan materials and water is also larger. This results to a better hydration process and increase the workability of concrete. The gaps between the particles of aggregates are able to be filled up with micro fine sized POFA which provides lubrication for aggregates to settle.

Table 1.3: Size of sample from $\mathrm{BET}_{\mathrm{N} 2}$ method

\begin{tabular}{|l|l|l|l|l|}
\hline & $0 \%$ & $10 \%$ & $20 \%$ & $30 \%$ \\
\hline Average Pore Radius (nm) & 7.05 & 7.59 & 7.33 & 7.18 \\
\hline Total Pore volume (cc/g) & 0.02 & 0.03 & 0.03 & 0.02 \\
\hline Specific Surface area (m2/g) & 52.87 & 69.39 & 65.00 & 63.97 \\
\hline
\end{tabular}

\section{Conclusion and Recommendation}

Based on the results obtained from the experimental works on the production and characterization of micro fine sized palm oil fuel ash (POFA), the following conclusions can be made:

I. A simple yet effective method for laboratory scale production of micro fine sized POFA has been developed using a 25000-rpm electric powder grinder. The efficiency of this method achieved up to $96 \%$ production of micro fine sized POFA ranging between 1-10 $\mu \mathrm{m}$ of median particle size $\left(d_{50}\right)$ when the optimum grinding process is used.

II. The microstructural analyses of the cement paste show formation of $\mathrm{C}-\mathrm{S}-\mathrm{H}$ gel as hydrated product is with the strongest band when $20 \%$ of the micro fine sized POFA replacement is utilized. Highest compressive strength together with $\mathrm{Ca} / \mathrm{Si}$ ratio is also achieved indicating pozzolanic characteristics. $\mathrm{BET}_{\mathrm{N} 2}$ test gives average pore radius of $7.3 \mathrm{~nm}$ with specific surface area of $65 \mathrm{~m}^{2} / \mathrm{g}$.

The results obtained indicate that the new approach using an electric powder grinder is successful in producing micro fine size POFA and this approach is envisaged applicable for used in the industry provided further modification is carried out in future work to increase the efficiency if this device.

\section{Acknowledgement}

This research is funded by Osaka Gas Foundation in Cultural Exchange Research Grant (OGFICE) session 2014/2015.

\section{References}

1. Usman, J., Zaky, M., \& Arifin, Z. (2014). Effects of Palm Oil Fuel Ash Composition on the Properties and Morphology of Porcelain-palm Oil Fuel Ash Composite. Jurnal Teknologi Full paper 5, 5-10.

2. Abdul Awal, a. S. M., \& Hussin, M. (2011). Effect of palm oil fuel ash in controlling heat of hydration of concrete. Procedia Engineering, 14, 2650-2657.

3. Ahmadi, R., Zainudin, N., Ismail, I., Mannan, M.A. \& Abidin, A.S.Z. (2016). Micro fine sized Palm Oil Fuel Ash (POFA) produced using a wind tunnel production system. Journal of Advances in Materials Science and Engineering. Volume 2016, Article ID 6792731

4. Abdullah, K., \& Hussin, M. (2010). Fire Resistance Properties of Palm Oil Fuel Ash Cement Based Aerated Concrete, 1(September), 107-114.

5. Usman, J., Zaky, M., \& Arifin, Z. (2014). Jurnal Teknologi Full paper Effects of Palm Oil Fuel Ash Composition on the Properties and Morphology of Porcelainpalm Oil Fuel Ash Composite, 5, 5-10.

6. Muthusamy, K., \& Azzimah, Z. N. (2014). Exploratory Study of Palm Oil Fuel Ash as Partial Cement Replacement in Oil Palm 
Shell Lightweight Aggregate Concrete, 8(2), 150-152.

7. Kroehong, W., Sinsiri, T., \& Jaturapitakkul, C. (2011). Effect of palm oil fuel ash fineness on packing effect and pozzolanic reaction of blended cement paste. Procedia Engineering, 14, 361-369.

8. Olalekan, M., Universiti, Y., \& Tebal, N. (2014). Improving the Engineering and Fluid Transport Properties of Ultra-High Strength Concrete Utilizing Ultrafine Palm Oil Fuel Ash Improving the Engineering and Fluid Transport Properties of UltraHigh Strength Concrete Utilizing Ultrafine Palm Oil Fuel, (October 2015).

9. Oss, H.G., \& Padovani, A.C. (2003). Cement manufacture and the Environment - Part II: Environmental challenges and opportunities. Journal of Industrial Ecology, 7(1), 93-126.

10. Bensted, J. \& Barnes, P. (2008). Structure and Performance of Cements, 2nd edition, Taylor and Francis Group, London and Newyork.
11. Awal, A.S.M. and Hussin, M.W. (1997) Some Aspects of Durability Performances of Concrete Incorporating Palm Oil Fuel Ash, Proceedings of the Fifth International Conference on Structural Failure, Durability and Retrofitting, Singapore, 210-218.

12. Mannan, A. Asrah, H., \& Mirasa, A. K. (2015). The Performance of Ultrafine Palm Oil Fuel Ash in Suppressing the Alkali Silica Reaction in Mortar Bar, International Journal of Engineering and Applied Sciences (IJEAS) (9), 60-66.

13. Johari, M. A. M., Zeyad, A. M., Yusuf, M. O. (2014). Improving the Engineering and Fluid Transport Properties of Ultra-High Strength Concrete Utilizing Ultrafine Palm Oil Fuel Ash. Journal of Advanced Concrete Technology. 12, 127-137.

14. Yahaya, F. M., Muthusamy, K., \& Sulaiman, N. (2014). Corrosion Resistance of High Strength Concrete Containing Palm Oil Fuel Ash as Partial Cement Replacement, 7(22), 4720-4722. 